\title{
Chlorofluorocarbene: First UV Observation of a Dihalocarbene in Solution
}

Robert A. Moss*, Jingzhi Tian, Ronald R. Sauers, Christopher Skalit, and Karsten Krogh-Jespersen*

Department of Chemistry \& Chemical Biology, Rutgers, The State University of

New Jersey, New Brunswick, New Jersey 08903 
1. ${ }^{1} \mathrm{H}$ NMR of 2,4-dinitrophenoxyfluorodiazirine, $\mathbf{1 0}$

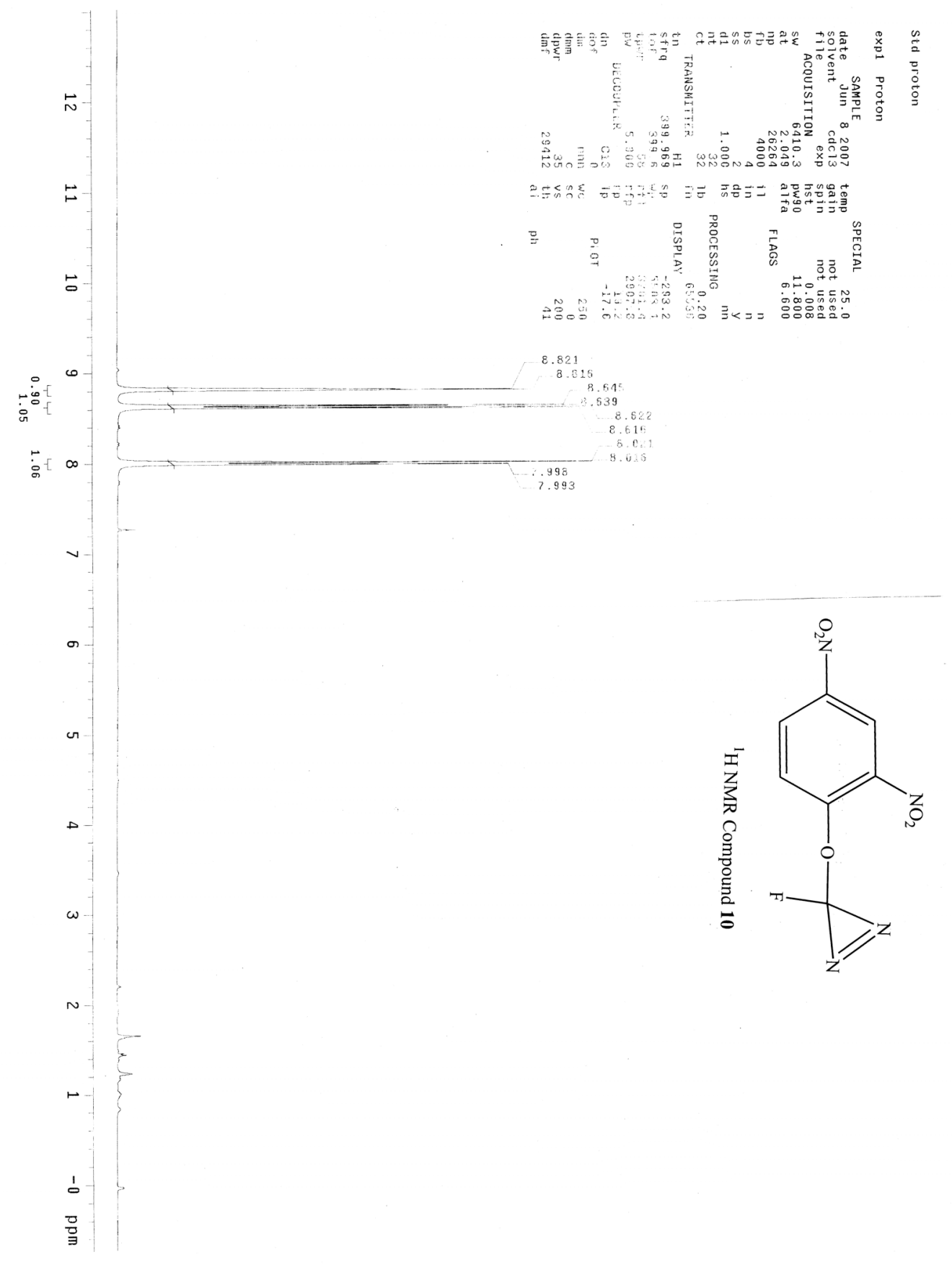


2. ${ }^{13} \mathrm{C}$ NMR of 2,4-dinitrophenoxyfluorodiazirine, 10

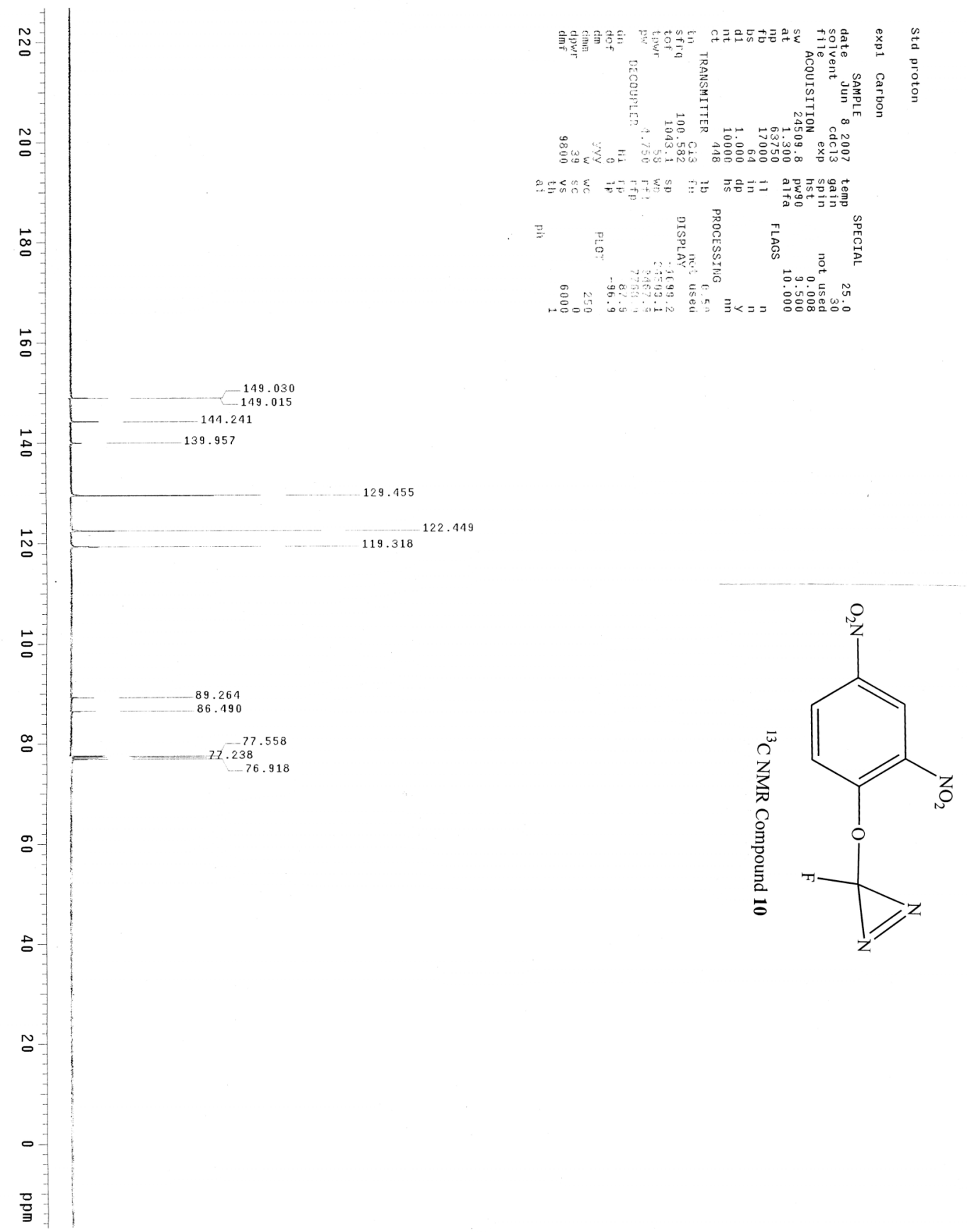


3. ${ }^{19} \mathrm{~F}$ NMR of 2,4-dinitrophenoxyfluorodiazirine, 10

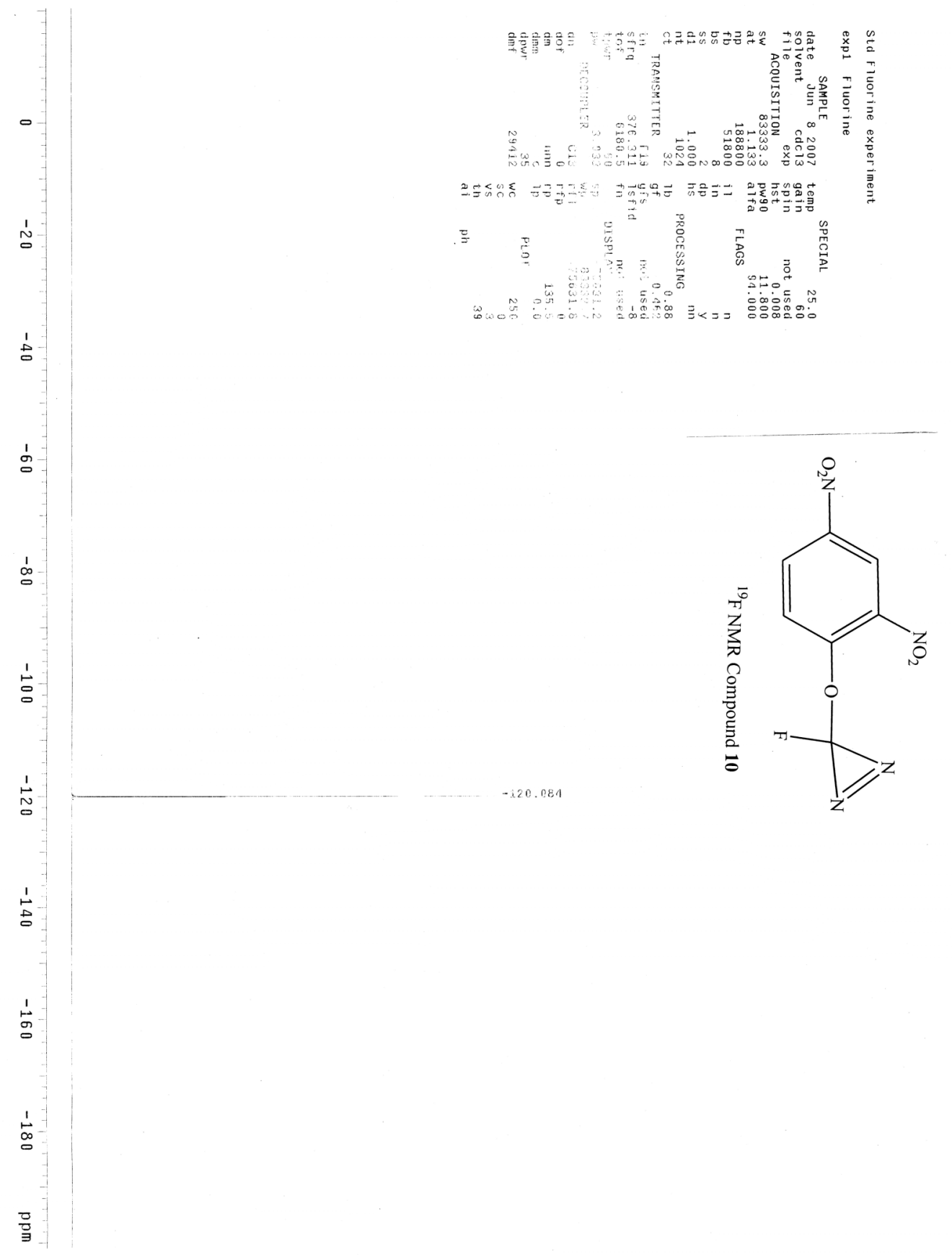




\section{4. ${ }^{1} \mathrm{H}$ NMR of phenoxychlorodiazirine, 8}

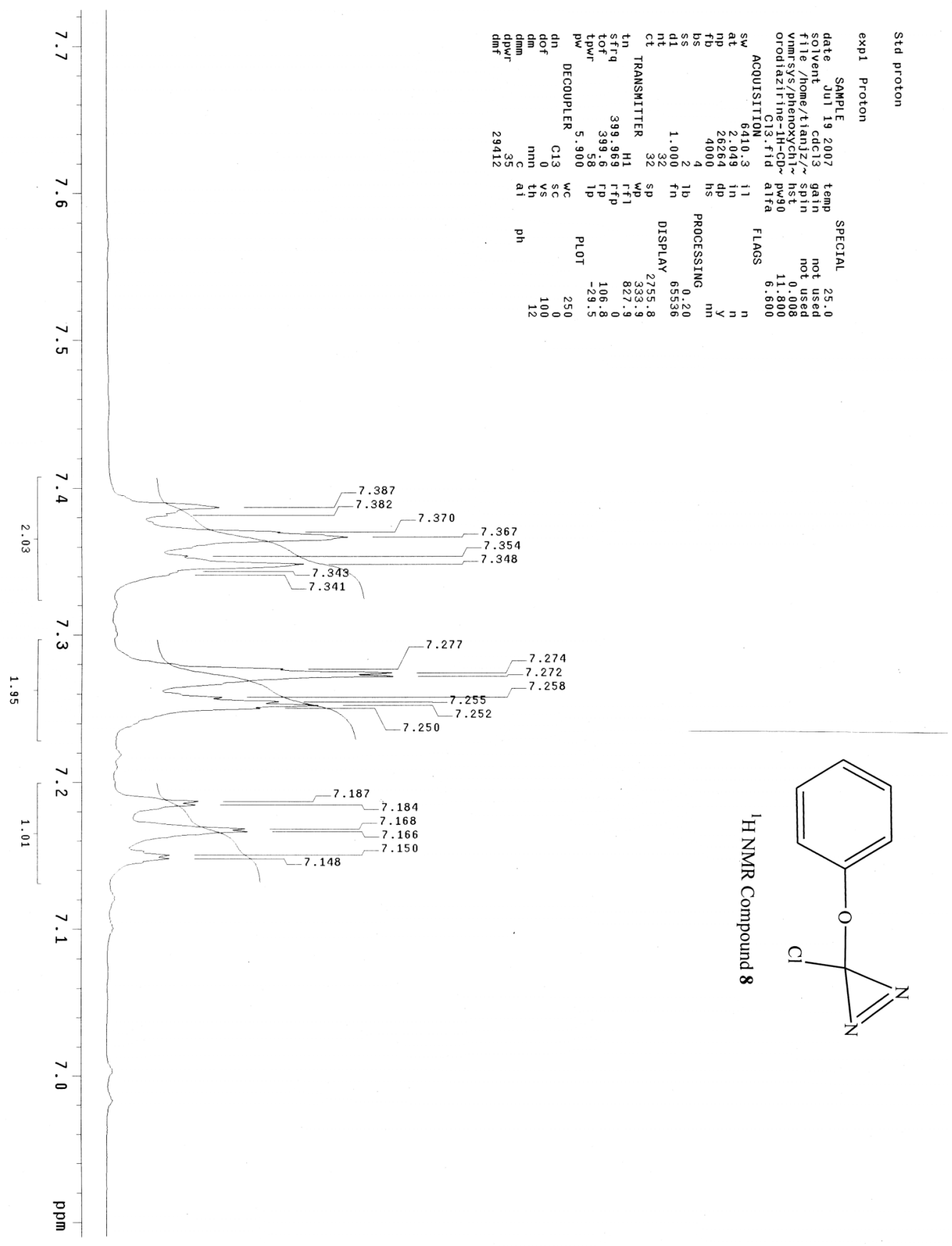


5. ${ }^{13} \mathrm{C}$ NMR of phenoxychlorodiazirine, 8

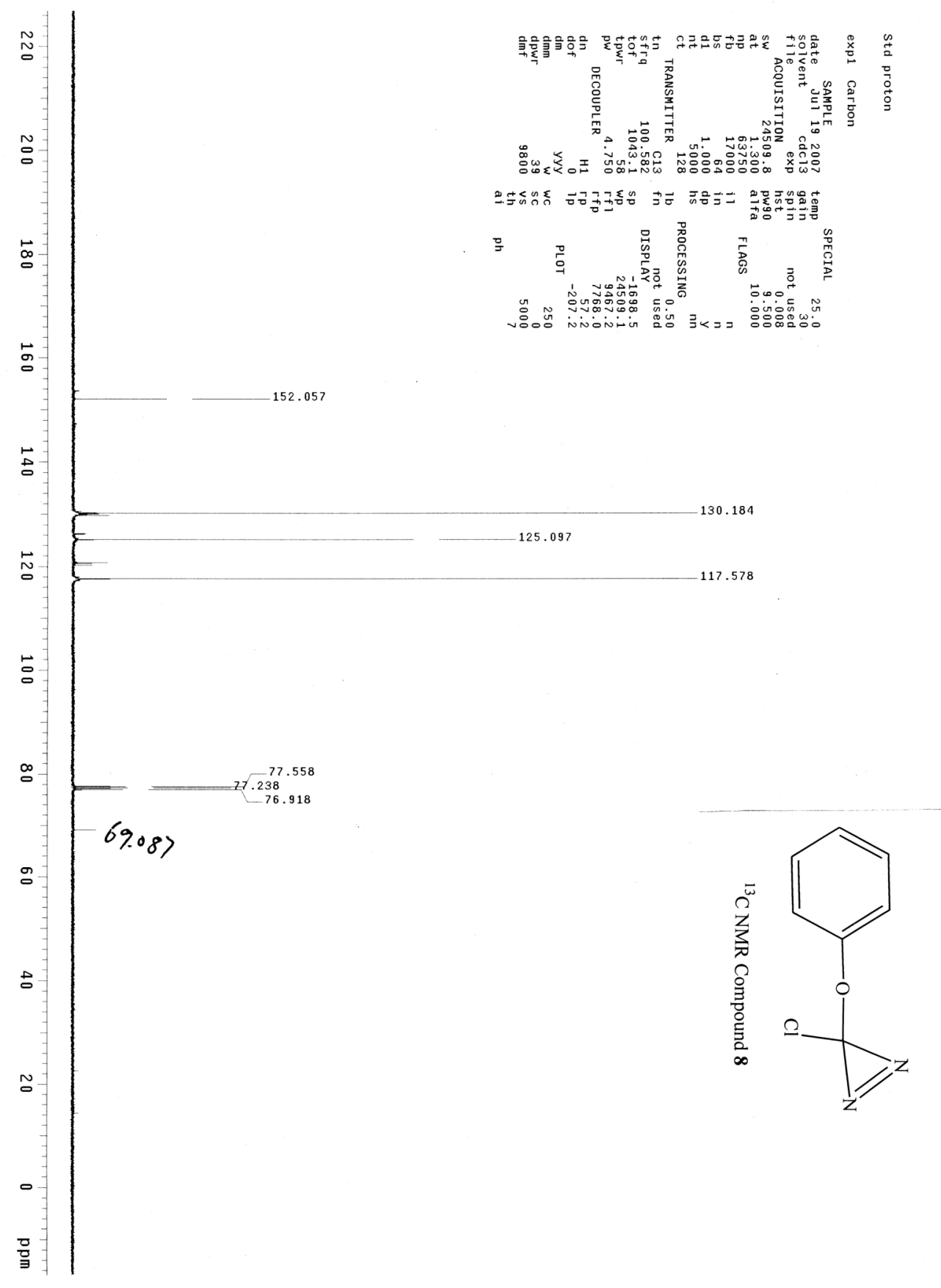


6. ${ }^{19} \mathrm{~F}$ NMR of chlorofluorodiazirine, 1

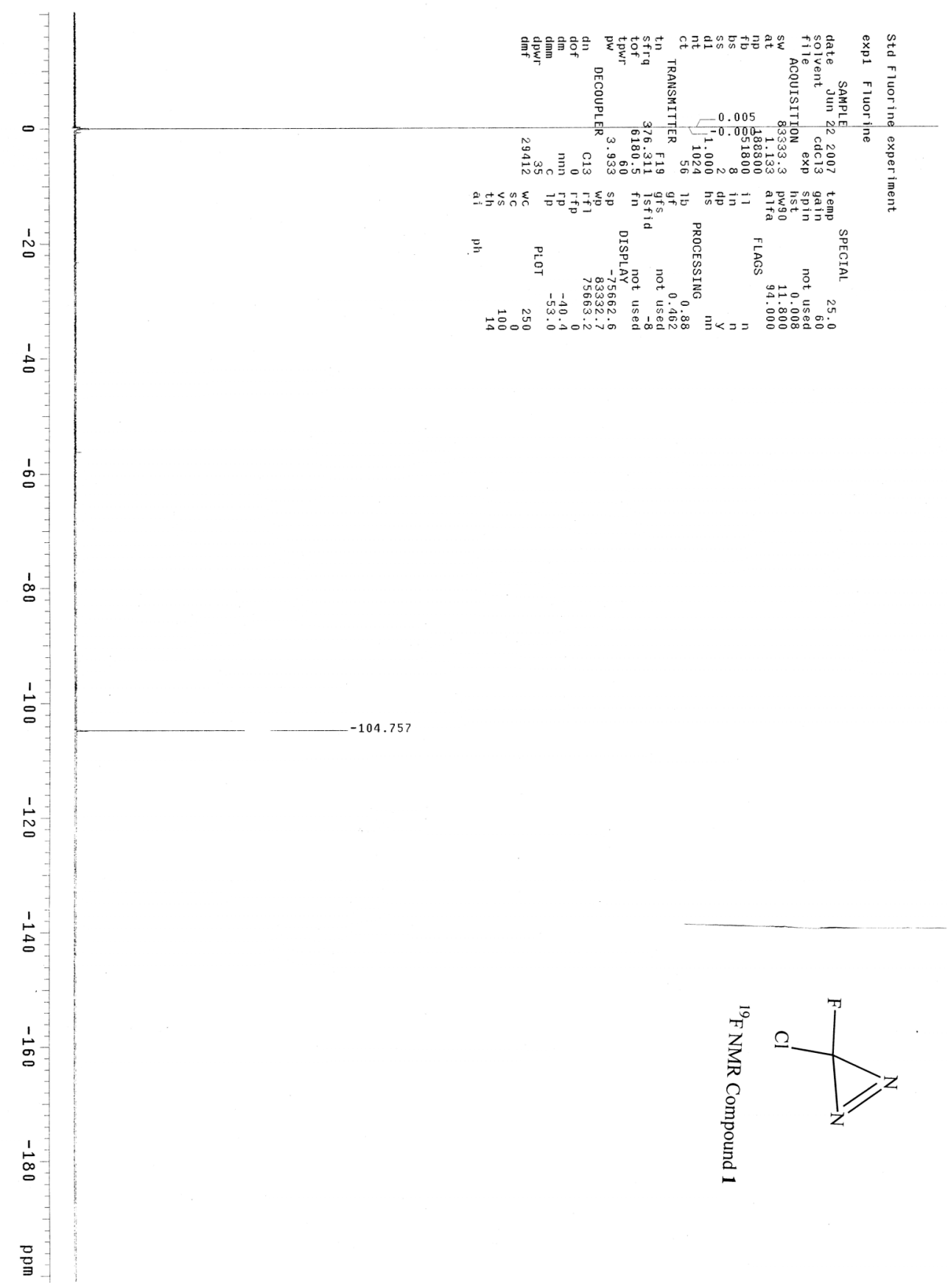

